\title{
Determinants of Productive Efficiency of Public Service: What Effect of the Interaction of Corruption Control and Average Wage?
}

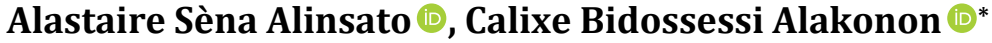 \\ Laboratory of Public Economics, University of Abomey-Calavi, Abomey-Calavi, Benin \\ Email: alastaires@yahoo.fr, *calixealakonon@yahoo.com
}

How to cite this paper: Alinsato, A. S., \& Alakonon, C. B. (2021). Determinants of Productive Efficiency of Public Service: What Effect of the Interaction of Corruption Control and Average Wage? Theoretical Economics Letters, 11, 1055-1066. https://doi.org/10.4236/tel.2021.116067

Received: February 8, 2021

Accepted: November 9, 2021

Published: November 12, 2021

Copyright $\odot 2021$ by author(s) and Scientific Research Publishing Inc. This work is licensed under the Creative Commons Attribution International License (CC BY 4.0).

http://creativecommons.org/licenses/by/4.0/

\begin{abstract}
This paper seeks to analyze the determinants of the civil service productive efficiency in West African Economic Monetary Union (WAEMU) countries over the period 2003-2017. Using the two-stage Data Envelopment Analysis (DEA) model, our results show that the average productive efficiency of the public services studied is $87.4 \%$. This suggests that there is room for improvement in the level of output of the public services, all other things being equal. We also found that the average wage, the square of corruption control, and the interaction term between corruption control and the average wage have a positive effect on productive efficiency. These findings suggest that before getting improvement in the productive efficiency of public service in the WAEMU region, countries should reach a higher level of corruption control and a substantial level of the average wage.
\end{abstract}

\section{Keywords}

Productive Efficiency, Public Service, Governance, DEA, WAEMU

\section{Introduction}

The efficiency of public intervention is an important concern in economic analysis. There is a controversy among economists about the legitimacy and efficiency of state action. For statist economists, public intervention could be efficient. Liberals, on the other hand, believe that all state action is inefficient and wasteful of resources. Thus, for them, state action lacks rationality and leads to an inefficient allocation of resources because the state is not guided by the profit motive.

In the provision of public goods and services, the state uses a certain amount 
of financial resources, but mainly the civil service, which represents all the workers in the public administration, who operate within the framework of the law (Bacache-Beauvallet \& Outin, 2013). But the seminal work of Buchanan and Tullock (1962) showed that the production of public goods by the public service is not efficient. This can be explained by the fact that public servants (bureaucrats), like all private agents, seek the greatest possible personal satisfaction on the one hand. On the other hand, they are subject to a system of weak control in the administration. This leads to inefficient production of public goods and services. They, therefore, propose a strict institutional framework for public policies to limit waste. In this sense, there is an emergence in economic analysis of empirical work to identify the explanatory factors of the efficiency of public production units.

Monkam (2014) examined the productive efficiency of local municipalities and its determinants in South Africa by explaining efficiency scores in a second stage using a Tobit regression model. He notes that fiscal autonomy, the number, and skill levels of senior managers positively influence the productive efficiency of municipalities in South Africa. Thus, an improvement in these factors is an important determinant of the improvement in the productive efficiency of municipalities. On the other hand, the results show a negative effect of local democratic behavior and vacancy rates on the efficiency of municipalities in South Africa.

Similarly, Štastná and Gregor (2014) studied public sector efficiency during and beyond government transition in the Czech Republic during the 1995-1998 transition period and the 2005-2008 post-transition period by identifying the determinants of local government efficiency by period. The results show that in both periods the size of the municipality and the main budgetary variables qualitatively affect efficiency in the same direction and in line with the fiscal stress hypothesis. However, it is during the post-transition period that geographical distances start to matter for efficiency.

Apart from local governments, other studies identifying the determinants of the productive efficiency of public production units focus on other sectors like education, health, justice, etc.

For example, in the health sector, Castaldo et al. (2020) investigated the determinants of health sector efficiency in 30 OECD countries using a two-stage method. Efficiency scores are calculated by the data envelopment method (DEA) in the first step. In the second step, they examined the determinants of the efficiency scores by a Tobit model. Their findings note inefficiencies in health service provision in OECD countries. Furthermore, the study shows that health inefficiency depends on the level of GDP per capita, immunization coverage, and tobacco consumption. But also, the inefficiency of the health system is explained by geographical and institutional factors of countries.

In the same sense, Chu et al. (2015) examined the efficiency and its determinants for the medical care system in China with the Tobit model. The results 
show that medical insurance reforms improved the performance of Chinese hospitals, while government subsidies decreased it. Provinces with higher GDP per capita and population density have better hospital performance. They suggest that the development of private hospitals should be encouraged, expanding the coverage of medical services. Similarly, Kaya Samut and Cafri (2015) work on the determinants of health system efficiency in OECD countries by the DEA and Tobit panel, shows that income, education level, and the number of private hospitals positively affect the productive efficiency of hospitals in OECD countries.

In the education sector, results of studies on socio-institutional determinants of the efficiency of educational resources according to the capability approach in Italy by Guarini et al. (2020) show on the one hand that there is inefficiency in the use of educational resources. On the other hand, the results suggest that social capital and the quality of governance positively influence the efficiency of educational resources. Also, the findings suggest complementarity between private wealth and public expenditure on education.

This literature shows that public units of production of goods and services often lack efficiency. Besides, the level of efficiency of these units is explained by socio-economic, political, and institutional factors. This shows that the debate on the determinants of public service efficiency is still relevant.

For several decades, all countries, and in particular the countries of the West African Economic and Monetary Union (WAEMU), adopted measures to increase the efficiency of the public service, notably in terms of salaries and the fight against corruption. However, the quality of public services is still relatively low for the provision of public goods and services in WAEMU countries. The average rating of the quality of the public service for the efficient provision of public goods over the period 2005 to 2018 is 2.88 for the WAEMU on a scale of 1 to 6 . This is lower than the rate for middle-income countries, which is 3.01 (World Bank, 2020).

Based on these theoretical and empirical findings, on the one hand, and the context and stylized facts, on the other hand, the question of; what are the determinants of the productive efficiency of the civil service in WAEMU countries is asked?

The objective of this paper is to examine the determinants of the productive efficiency of the public service in WAEMU countries. To the best of our knowledge, no study on the determinants of public sector efficiency in the WAEMU has specifically examined the determinants of the productive efficiency of the public service. Thus, this study will identify the factors that influence the level of efficiency, and assess the effect of the interaction between the control of corruption and the average wage to orient economic policies. To do this, we will use the two-stage Data Envelopment Analysis (DEA) model. First, we will calculate efficiency scores, and second, we will study the determinants of efficiency.

The rest of this paper is organized into three parts. The first part presents the methodological approach. The second part discusses the results obtained and fi- 
nally a conclusion.

\section{Methodological Approach}

\subsection{First Step: Method for Determining the Efficiency}

The determination of the efficiency of a decision or production unit is generally based on the analysis of the production frontier since the early ideas of Koopmans (1951) and Debreu (1951) with the seminal work of Farrell (1957) on the calculation of efficiency. In the literature, we find that the DEA method is more compatible for the determination of the efficiency of the public service because of the existence of multiple inputs and outputs for production on the one hand. On the other hand, the production technology is difficult to model and prices are not known. Indeed, in the situation of a multi-input, multi-output technology, the efficiency can be written thus:

$$
\begin{gathered}
E T_{k}=\frac{\sum_{r=1}^{s} U_{r} Y_{r k}}{\sum_{i=1}^{m} V_{i} X_{i k}} \\
\text { With }\left(0<E T_{k} \leq 1\right)
\end{gathered}
$$

where $E T_{k}$ is the productive efficiency of production unit $k$ using $\mathrm{m}$ inputs to produce $s$ outputs; $Y_{r k}$ is the quantity of output $r$ produced by production unit $k, X_{i k}$ is the quantity of input $i$ consumed by production unit $k, U_{r}$ and $V_{i}$ the respective weights of output $r$ and input $i ; n$ is the number of production units to be evaluated; $m$ and $s$ are the respective numbers of inputs and outputs.

The use of the DEA approach will aim to estimate the ratio between the weighted sum of outputs and the weighted sum of inputs for each production unit under study. Each decision unit will want to maximize, and if it reaches the frontier, the value of the ratio will be equal to unity and contrarily, the value will be less than unity.

If we are in the presence of $\mathrm{n}$ production units, the mathematical program to solve would be:

$$
\begin{gathered}
\max \frac{\sum_{r=1}^{s} U_{r} Y_{r k}}{\sum_{i=1}^{m} V_{i} X_{i k}} \\
\mathrm{U} / \mathrm{C}\left\{\begin{array}{l}
\frac{\sum_{r=1}^{s} U_{r} Y_{r k}}{\sum_{i=1}^{m} V_{i} X_{i k}} \leq 1 \\
U_{r}, V_{i} \geq 0 \\
r=1, \cdots, s ; i=1, \cdots, m \text { and } j=1, \cdots, n
\end{array}\right.
\end{gathered}
$$

The optimization system can be solved according to two options. The first, output orientation, is to maximize the weighted sum of outputs while keeping inputs fixed. This implies how much a decision unit can increase its output with the same amount of inputs. The second option, which represents the input orientation, consists of minimizing the weighted sum of inputs while keeping the outputs fixed. In other words, it shows the proportion in which a production 
unit can reduce its inputs while producing the same volume of outputs (Huguenin, 2013).

In this paper, we adopt the output-oriented DEA approach with variable returns to scale (VRS) which is presented as follows (Banker et al., 1984):

$$
\begin{gathered}
\quad \max \varnothing_{k}+\varepsilon \sum_{r=1}^{s} S_{r}+\varepsilon \sum_{i=1}^{m} S_{i} \\
\text { Subject to }\left\{\begin{array}{l}
\varnothing_{k} y_{r k}-\sum_{r=1}^{n} \lambda_{j} y_{r j}+S_{r}=0, r=1, \cdots, s \\
x_{i k}-\sum_{j=1}^{n} \lambda_{j} x_{i j}-S_{r}=0, r=0, i=1, \cdots, m \\
\lambda_{j} ; S_{r} ; S_{i} \geq 0 \quad \forall j=1, \cdots, n ; r=1, \cdots, s ; i=1, \cdots, m \\
\sum_{j=1}^{n} \lambda_{j}=1
\end{array}\right.
\end{gathered}
$$

It is to incorporate the variable returns to scale (VRS) assumption that the constant returns to scale (CRS) model is modified by relaxing the constant returns to scale assumption by adding a returns to scale measure $\left(\sum_{j=1}^{n} \lambda_{j}=1\right)$ that represents the convexity constraint in the dual equation for the decision unit.

\subsection{Step Two: Method for Estimating the Determinants of Productive Efficiency}

In the literature, the sensitivity of efficiency scores to certain socio-economic variables is an important concern. To assess the influence of these variables on the efficiency of production units, the Tobit regression model is commonly used because the efficiency score variable to be explained is censored (Lee, Lee, \& Kim, 2009; Ferrera et al., 2011; Qiao et al., 2017).

The model is as follows:

$$
E T_{k}=\left\{\begin{array}{lc}
\beta_{j} X_{k}+U_{k} ; & \text { si } E T^{*}>1 \\
0 & \text { if not }
\end{array}\right.
$$

$E T_{k}$ is the efficiency score of the public service and $X_{k}$ is the vector of determinants.

The functional form of the model is as follows:

$$
\begin{aligned}
& \text { score }_{i t}=f\left(\text { Corr }_{i t} ; \text { Efgour }_{i t} ; \text { VoixResp }_{i t} ; \text { Salmoy }_{i t} ; \text { Depinv }_{i t} ; \text { TPop }_{i t} ;\right. \\
&\text { Corr } \left.* \text { Salmoy }_{i t} ; \text { Corr }^{2} ; \text { Efgour }^{2}\right)
\end{aligned}
$$

\subsection{Variables and Data Source}

For this study, our data covers five WAEMU countries over the period 2003 to 2017, namely: Benin, Burkina-Faso, Niger, Senegal, and Togo. The choice of variables is based on the literature (Table 1).

\section{Empirical Results}

\subsection{Efficiency by Output Orientation}

Table 2 presents the productive efficiency scores of the public services of the five 
Table 1. Description of variables.

\begin{tabular}{|c|c|c|}
\hline Variables & Nature & sources \\
\hline Number of civil servants (AE) & Input & $\begin{array}{l}\text { Statistical Yearbook of the Ministry of } \\
\text { Public Service of WAEMU countries }\end{array}$ \\
\hline Equipment costs (FREQUIP) & Input & CBWAS and World Bank statistical yearbook \\
\hline GDP growth rate (TCPIB) & Output & World Bank \\
\hline Human Development Index (IDH) & Output & World Bank \\
\hline Corruption control (CORR) & Determinant & World Bank \\
\hline Government efficiency (EFGOUR) & Determinant & World Bank \\
\hline Voice and Responsibility (VOIXRESP) & Determinant & World Bank \\
\hline Average annual wage (SALMOY) & Determinant & Calculated \\
\hline Population growth rate (TPOP) & Determinant & World Bank \\
\hline $\begin{array}{l}\text { Interaction of Wages and Corruption } \\
\text { Control (CORR }{ }^{\star} \text { SALMOY) }\end{array}$ & Determinant & Calculated \\
\hline Square of Corruption control $\left(\mathrm{CORR}^{2}\right)$ & Determinant & Calculated \\
\hline Government efficiency square (EFGOUR $\left.{ }^{2}\right)$ & Determinant & Calculated \\
\hline
\end{tabular}

Auteurs (2021).

Table 2. Estimation results of the efficiency scores (output orientation)

\begin{tabular}{lcccccc}
\hline Years & \multicolumn{2}{c}{ Benin Senegal Niger } & \multicolumn{5}{c}{ Burkina-Faso Togo Average/year } \\
\hline 2003 & 0.9140 & 0.895 & 0.671 & 0.767 & 1 & 0.849 \\
2004 & 0.907 & 0.845 & 0.569 & 0.638 & 0.993 & 0.790 \\
2005 & 0.922 & 0.851 & 0.665 & 0.825 & 0.993 & 0.851 \\
2006 & 0.922 & 0.839 & 0.759 & 0.727 & 1 & 0.849 \\
2007 & 0.974 & 0.857 & 0.624 & 0.713 & 1 & 0.834 \\
2008 & 0.919 & 0.872 & 1 & 0.813 & 0.962 & 0.913 \\
2009 & 0.936 & 0.869 & 0.650 & 0.711 & 1 & 0.833 \\
2010 & 0.932 & 0.884 & 0.869 & 0.750 & 1 & 0.887 \\
2011 & 0.935 & 0.903 & 0.672 & 0.821 & 0.998 & 0.866 \\
2012 & 0.950 & 0.923 & 1 & 0.813 & 1 & 0.937 \\
2013 & 1 & 0.923 & 0.730 & 0.795 & 0.989 & 0.887 \\
2014 & 1 & 0.958 & 0.808 & 0.788 & 1 & 0.911 \\
2015 & 0.988 & 0.954 & 0.698 & 0.788 & 1 & 0.886 \\
2016 & 0.988 & 0.972 & 0.732 & 0.828 & 1 & 0.904 \\
2017 & 1 & 1 & 0.726 & 0.845 & 1 & 0.914 \\
Average & 0.952 & 0.903 & 0.745 & 0.775 & 0.995 & 0.874 \\
Average inefficiency & 0.048 & 0.097 & 0.255 & 0.225 & 0.005 & 0.126 \\
\hline
\end{tabular}

Auteurs (2021). 
WAEMU countries studied. On average over the study period, the efficiency score is $87.4 \%$ in terms of productive efficiency. This shows that there is still room for improvement in the production of public goods and services in these countries without an increase in production capacity. Indeed, the five countries could increase the output of their respective public services by $12.6 \%$ without recruiting more civil servants or increasing the capital expenditure of public administrations.

This lack of efficiency in the public service in the WAEMU could be explained by the socio-economic and institutional characteristics of the countries. It is, therefore, necessary to study the influence of these factors to formulate economic policy measures that will improve the level of productive efficiency of the public service in the countries. This is important because of the difficulties that countries are facing. Resources are increasingly scarce but there is a growing need for the population to be satisfied by the state. Therefore, states need to allocate resources efficiently to avoid wastage which can compromise the economic performance of countries.

\subsection{Determinants of Public Service Efficiency Scores}

To assess the statistical basis of the efficiency scores calculated by the DEA method, we carried out a second step estimation to identify the exogenous factors that influence the efficiency scores.

The efficiency scores generated by the DEA method are censored (between 0 and 1) but no decision unit has a score of zero. To take this aspect into account, we estimated the Tobit model by the maximum likelihood method on the one hand, and on the other hand, a Fractional Probit Regression on the productive efficiency of the public functions studied. The coefficient of the Akaike's information criterion (AIC) test of the Tobit model $(-173.8077)$ is lower than that of the fractional probit regression (63.42293), so the Tobit model is more appropriate.

To ensure the robustness of these results, we also estimated them using the double bootstrap method proposed by Simar and Wilson (2007), which allows us to take into account the following two limitations: On the one hand, the technical efficiency scores generated by the DEA method are statistically and strongly dependent on each other, which implies a serial correlation of the error term. On the other hand, the explanatory variables of technical efficiency tend to be correlated with the error term. Thus, we opted for Algorithm 1 because of our small sample size.

The estimation is done according to two approaches. In approach 1 we estimated only the variables without the squares of the variables; control of corruption and government effectiveness. In approach 2, the estimation is done by replacing the variables; control of corruption and government effectiveness with their squares.

The maximum likelihood results of the Tobit model using both approaches 
and the double bootstrap method give us the same results reported in Table 3, implying that our estimates from the DEA approach are robust to alternative methodologies.

The results show that the coefficients on the variables of corruption control and government effectiveness are negatively significant. This shows that the more governments adopt measures to improve their efficiency and corruption control, the less the productive efficiency of the civil service in WAEMU countries improves. These results could be justified by the fact that improved government efficiency with reduced corruption leads to the limitation of personal rents of civil servants that can be considered as incentives. These results are consistent with the theoretical results of Lui (1985), Lien (1986), and Beck and Maher (1986) who established a positive effect between the development of corruption and the growth of labor productivity. For them, corruption generates additional income for workers and acts as an efficiency wage by improving the productive efficiency of public servants. Therefore, any economic policies to control corruption aimed at improving productive efficiency must take this factor

Table 3. Estimation results for the determinants of efficiency.

\begin{tabular}{|c|c|c|c|c|}
\hline \multirow{2}{*}{ Variables } & \multicolumn{2}{|c|}{$\begin{array}{c}\text { maximum likelihood of the } \\
\text { Tobit model }\end{array}$} & \multicolumn{2}{|c|}{$\begin{array}{c}\text { Bootstrap by Simar and } \\
\text { Wilson }(2007)\end{array}$} \\
\hline & Approach1 & Approach2 & Approach1 & Approach2 \\
\hline Corr & $\begin{array}{c}-0.341^{\star * *} \\
(-2.84)\end{array}$ & - & $\begin{array}{l}-0.295^{\star * \star} \\
(-2.67)\end{array}$ & - \\
\hline Efgour & $\begin{array}{c}-0.188^{\star * *} \\
(-2.87)\end{array}$ & - & $\begin{array}{c}-0.245^{\star * *} \\
(-3.6)\end{array}$ & - \\
\hline Salmoy & $\begin{array}{c}5.99 \mathrm{e}-08^{* * *} \\
(4.05)\end{array}$ & $\begin{array}{c}3.44 \mathrm{e}-08^{* * *} \\
(2.95)\end{array}$ & $\begin{array}{c}6.47 \mathrm{e}-08^{* * *} \\
(4.3)\end{array}$ & $\begin{array}{c}4.17 \mathrm{e}-08^{* * *} \\
(3.82)\end{array}$ \\
\hline Depinv & $\begin{array}{c}0.008^{\star * *} \\
(3.46)\end{array}$ & $\begin{array}{c}0.007^{\star * *} \\
(3.32)\end{array}$ & $\begin{array}{c}0.006^{\star * *} \\
(2.84)\end{array}$ & $\begin{array}{c}0.005^{\star * *} \\
(2.84)\end{array}$ \\
\hline Voixresp & $\begin{array}{l}0.087^{\star *} \\
(2.11)\end{array}$ & $\begin{array}{c}0.124^{\star * *} \\
(2.72)\end{array}$ & $\begin{array}{c}0.115^{\star * *} \\
(2.81)\end{array}$ & $\begin{array}{c}0.145^{\star * *} \\
(3.31)\end{array}$ \\
\hline Tpop & $\begin{array}{l}-0.250^{\star * \star} \\
(-6.96)\end{array}$ & $\begin{array}{l}-0.205^{\star * \star} \\
(-5.36)\end{array}$ & $\begin{array}{l}-0.273^{\star * *} \\
(-7.44)\end{array}$ & $\begin{array}{l}-0.240^{\star * *} \\
(-6.02)\end{array}$ \\
\hline CorrSalmoy & $\begin{array}{c}7.02 \mathrm{e}-08^{\star *} \\
(2.32)\end{array}$ & $\begin{array}{l}1.22 \mathrm{e}-08 \\
(0.68)\end{array}$ & $\begin{array}{c}6.41 \mathrm{e}-08^{\star *} \\
(2.14)\end{array}$ & $\begin{array}{l}1.62 \mathrm{e}-08 \\
(0.92)\end{array}$ \\
\hline Corr2 & - & $\begin{array}{l}0.154^{*} \\
(1.70)\end{array}$ & - & $\begin{array}{c}0.161^{*} \\
(1.78)\end{array}$ \\
\hline Efgour2 & - & $\begin{array}{c}0.132^{\star * *} \\
(2,84)\end{array}$ & - & $\begin{array}{c}0.180^{\star * *} \\
(3,24)\end{array}$ \\
\hline Constant & $\begin{array}{c}1.075^{\star * *} \\
(10.89)\end{array}$ & $\begin{array}{c}1.123^{\star * *} \\
(11.09)\end{array}$ & $\begin{array}{c}1.159^{\star * *} \\
(13.47)\end{array}$ & $\begin{array}{c}1.231^{\star * *} \\
(13.23)\end{array}$ \\
\hline
\end{tabular}

Auteurs (2021) ${ }^{* * *},{ }^{* *}$ and ${ }^{*}$ indicate significance at the threshold of $1 \%, 5 \%$ and $10 \%$. 
into account so as not to limit the efficiency of the production of public goods in the short run.

In addition, the coefficient on the variable, vote, and accountability, is significant and has a positive effect on countries' efficiency scores. These results reveal that the higher the quality of the democracy indicators, the higher the efficiency of the public service. In other words, the more democratic a country is with good orientations, the more peace of mind, confidence, foresight, and relevance of the tasks to be performed by civil servants, and the more their efficiencies increase. The rationale would be that civil servants have less political pressure and they perform their tasks well. This is consistent with the study of Hwang and Akedede (2011) which found a positive relationship between the quality of a country's governance and the efficiency of the public sector in the areas of administration policy, infrastructure, and stability. Thus, there is a need to further promote democratic freedom in the public service to stimulate increased production efficiency.

The coefficient of the population growth rate is negatively significant, so high population growth is accompanied by high demand for public administration services. This gives civil servants more tasks and also requires capital expenditure for the state. These results are in line with those of Benito et al. (2019) who show that high population density has a negative effect on the efficiency of public goods provision.

The average annual salary variable has a positive and significant effect on the productive efficiency of the public service in WAEMU countries. Thus, the higher the average salary, the more the efficiency of civil servants will improve. This shows that a high salary level would be a motivating factor to improve the productivity of civil servants in the countries. This is explained by Akerlof (1982) theory of wage efficiency highlighted by Georgiadis (2012) in the UK with an experimental model that the minimum wage plays the role of efficiency wage, as well as Ehrenberg and Smith (2009) who showed that a better wage level can contribute to the improvement of workers' productivity and thus can play the role of an incentive for civil servants to improve production efficiency. Therefore, it is necessary to guarantee a sufficient salary for public service workers to have high production efficiency.

The results show that the interaction variable between corruption control and the average annual salary explains positively the productive efficiency of the civil service in the WAEMU. The positive effect of the increase in the average wage would dominate the negative effect of the control of corruption. Thus, the average wage plays a complementary role in the control of corruption to the benefit of improving the efficiency of civil servants. This could be justified by the fact that an increase in the average wage would compensate for the lack of individual rents due to the control of corruption which serves as an incentive bonus. This is because corruption is perceived as an efficiency wage that increases the productivity of poorly paid civil servants. This is consistent with the perception that corruption compensates for the failure of state institutions by generating indi- 
vidual rents to motivate workers (Leff, 1964; Leys, 1965; Bailey, 1966).

We also find that the variable public investment expenditure has a positive effect on the productive efficiency of the civil service in WAEMU countries. This result can be explained by the fact that the more the State carries out investment expenditure, the more there will be an improvement in the quality of infrastructure on the one hand, and on the other hand the accumulation of human capital, which will lead to an increase in worker productivity. This result is consistent with that of Lio and Liu (2008).

In contrast to the results of approach 2, the squares of the variables corruption control and government effectiveness positively influence the productive efficiency of the civil service in WAEMU countries. This is contrary to the effects of the variables themselves. Thus, there is a higher level of corruption control and government effectiveness that will improve the productive efficiency of the civil service of the countries. Thus, in the short run, public servants are resistant to corruption reduction reforms because of the loss of individual benefits that corruption generates. These results suggest that the control of corruption and government efficiency should be accelerated to a certain level before stimulating the improvement of the productive efficiency of the public service in the provision of public goods and services. Thus, to improve the productive efficiency of the public service, it is necessary to adopt measures to achieve a high level of improvement in the quality of governance. This corroborates with the results of the study led Hwang and Akedede (2011) which established a positive relationship between the quality of governance of a country and the efficiency of the public sector in the areas of administration policy, infrastructure, and stability.

\section{Conclusion}

In this work, we have studied the productive efficiency of the public service in Benin, Burkina Faso, Senegal, Niger, and Togo, which are responsible for producing public goods and services. Thus, we used the two-stage DEA method, which is more adapted to our study context where there are several inputs and outputs whose production technique is difficult to model. The determination of the efficiency scores shows that the average productive efficiency in these countries is $87.4 \%$. This shows that there is still room for improvement in the production of public goods and services in these countries without an increase in the means of production. This could be explained by socio-economic and institutional factors. The maximum likelihood estimation of the Tobit model and the bootstrap method of the determinants of the efficiency scores show that the results are identical. The results show that the variables: corruption control, government effectiveness, and population growth rate, negatively and significantly influence the efficiency scores of countries. While the variables average wage, public investment expenditure, vote, and accountability, the square of the variables corruption control and government effectiveness as well as the product of corruption control and average wage have a positive and significant sign on the 
efficiency scores. These results have policy implications. To reduce the negative effect of corruption control on efficiency, governments need to develop a comprehensive approach not only to fight corruption but also to improve wage levels in the short term and the long-term, act to achieve a high level of corruption control and government efficiency to discourage resistance from civil servants. Despite the policy implications of our results, it is worth noting that this paper did not take into account the potential slacks in inputs and outputs. Further studies may improve this methodological aspect.

\section{Conflicts of Interest}

The authors declare no conflicts of interest regarding the publication of this paper.

\section{References}

Akerlof, G. A. (1982). Labor Contracts as Partial Gift Exchange. The Quaterly Journal of Economics, 97, 543-569. https://doi.org/10.2307/1885099

Bacache-Beauvallet, M., \& Outin, J. L. (2013). L'emploi public: Nouveau systeme de regles, nouvelles strategies d'acteurs. Revue Francaise de Sciences Sociales, 121, 7-15. https://doi.org/10.4000/formationemploi.3903

Bailey, D. H. (1966). The Effects of Corruption in a Developing Nation. Western Political Quarterly, 19, 719-732. https://doi.org/10.1177/106591296601900410

Banker, R. D., Charnes, A., \& Cooper, W. W. (1984). Some Models for Estimating Technical and Scale Inefficiencies in Data Envelopment Analysis. Management Science, 30, 1078-1092. https://doi.org/10.1287/mnsc.30.9.1078

Beck, P. J., \& Maher, M. W. (1986). A Comparison of Bribery and Bidding in Thin Markets. Economics Letters, 20, 1-5. https://doi.org/10.1016/0165-1765(86)90068-6

Benito, B., Faura, Ú., Guillamón, M. D., \& Ríos, A. M. (2019). The Efficiency of Public Services in Small Municipalities: The Case of Drinking Water Supply. Cities, 93, 95-103. https://doi.org/10.1016/j.cities.2019.04.016

Buchanan, J. M. \& Tullock, G. (1962). The Calculus of Consent. Logical Foundations for Constitutional Democracy. University of Michigan Press.

Castaldo, A. et al. (2020). Determinants of Health Sector Efficiency: Evidence from a Two-Step Analysis on 30 OECD Countries. Economics Bulletin, 40, 1651-1666.

Chu, K. (2015). The Efficiency and Its Determinants for China's Medical Care System: Some Policy Implications for Northeast Asia. Sustainability, 7, 14092-14111. https://doi.org/10.3390/su71014092

Debreu, G. (1951). The Coefficient of Resource Utilization. Econometrica, 19, 273-292. https://doi.org/10.2307/1906814

Ehrenberg, R. G., \& Smith, R. S. (2009). Modern Labor Economics: Theory and Public Policy (11th ed.). Pearson Education.

Farrell, M. J. (1957). The Measurement of Productive Efficiency. Journal of the Royal Statistical Society, Series A (General), 120, 253-290. https://doi.org/10.2307/2343100

Ferrera, J. M. C., Chaparro, F. P., \& Jiménez, J. S. (2011). Evaluation de l'efficience des services cadastraux au moyen de l'AED. Revue Internationale des Sciences Administratives, 77, 837-859. 
Georgiadis, A. (2012). Efficiency Wages and the Economic Effects of the Minimum Wage: Evidence from a Low-Wage Labour Market. Oxford Bulletin of Economics and Statistics, 75, 962-979. https://doi.org/10.1111/j.1468-0084.2012.00713.x

Guarini, G., Laureti, T., \& Garofalo, G. (2020). Socio-Institutional Determinants of Educational Resource Efficiency According to the Capability Approach: An Endogenous Stochastic Frontier Analysis. Socio-Economic Planning Sciences, 71, Article ID: 100835 https://doi.org/10.1016/j.seps.2020.100835

Huguenin, J. M. (2013). Data envelopment Analysis (DEA), Un guide pédagogique à l'intention des décideurs dans le secteur public. IDHEAP-Cahier, 278, 7-81.

Hwang, J., \& Akdede S. H. (2011). The Influence of Governance on Public Sector Efficiency: A Cross-Country Analysis. The Social Science Journal, 48, 735-738. https://doi.org/10.1016/j.soscij.2011.04.002

Kaya Samut, P., \& Cafri, R. (2015). Analysis of the Efficiency Determinants of Health Systems in OECD Countries by DEA and Panel Tobit. Social Indicators Research, 129, 113-132. https://doi.org/10.1007/s11205-015-1094-3

Koopmans, T. C. (1951). An Analysis of Production as an Efficient Combination of Activities. In T. C. Koopmans (Ed.), Activity Analysis of Production and Allocation, Cowles Commission for Research in Economics, Monograph No. 13 (pp. 33-97). Wiley.

Lee C., Lee J., \& Kim, T. (2009). Innovation Policy for Defense Acquisition and Dynamics of Productive Efficiency, A DEA Application to the Korean Defense Industry. Asian Journal of Technology Innovation, 17, 151-171. https://doi.org/10.1080/19761597.2009.9668677

Leff, N. (1964). Economic Development though Bureaucratic Corruption. The American Behavioural Scientist, 8, 8-14. https://doi.org/10.1177/000276426400800303

Leys, C. (1965). What Is the Problem about Corruption? Journal of Modern African Studies, 3, 215-230. https://doi.org/10.1017/S0022278X00023636

Lien, D. H. (1986). A Note on Competitive Bribery Games. Economics Letters, 22, 337-341. https://doi.org/10.1016/0165-1765(86)90093-5

Lio, M., \& Liu, M. C. (2008). Governance and Agricultural Productivity: A Cross-National Analysis. Food Policy, 33, 504-512. https://doi.org/10.1016/j.foodpol.2008.06.003

Lui, F. T. (1985). An Equilibrium Queuing Model of Bribery. Journal of Political Economy, 93, 760-781. https://doi.org/10.1086/261329

Monkam, N. F. (2014). Local Municipality Productive Efficiency and Its Determinants in South Africa. Development Southern Africa, 31, 275-298.

https://doi.org/10.1080/0376835X.2013.875888

Qiao, H., Shao, Y., Shi, J., Yang, W., \& Wang, S. (2017). Regional Technical Efficiency of Chinese Iron and Steel Industry Based on Bootstrap Network Data Envelopment Analysis. Socio-Economic Planning Sciences, 57, 14-24. https://doi.org/10.1016/j.seps.2016.07.003

Simar, L., \& Wilson, P. W. (2007) Estimation and Inference in Two-Stage, Semi-Parametric Models of Production Processes. Journal of Econometrics, 136, 31-64. https://doi.org/10.1016/j.jeconom.2005.07.009

Štastná, L., \& Gregor, M. (2014). Public Sector Efficiency in Transition and Beyond: Evidence from Czech Local Governments. Applied Economics, 47, 680-699. https://doi.org/10.1080/00036846.2014.978077

World Bank (2020, July). World Development Indicators-Data. World Development Indicators. 